\title{
Bio-based Flexible Network Polymer from Epoxidized Soybean Oil Reinforced by Poly(butyl methacrylate)
}

\author{
Nao Hosoda ${ }^{1}$, Hisao Hayashi ${ }^{2}$, Takashi Tsujimoto ${ }^{1}$ \\ ${ }^{1}$ Department of Applied Chemistry, Graduate School of Engineering, Osaka University, Yamadaoka 2-1, Suita, Osaka \\ 565-0871, Japan \\ ${ }^{2}$ Department of Materials Chemistry, Faculty of Science and Technology, Ryukoku University, Seta, Otsu 520-2194, \\ Japan \\ Correspondence: Takashi Tsujimoto, Department of Applied Chemistry, Graduate School of Engineering, Osaka \\ University, Yamadaoka 2-1, Suita, Osaka 565-0871, Japan. E-mail: tsujimoto@ chem.eng.osaka-u.ac.jp
}

Received: December 29, 2015 Accepted: January 16, 2016 Online Published: January 25, 2016

doi:10.5539/ijc.v8n1p159

URL: http://dx.doi.org/10.5539/ijc.v8n1p159

\begin{abstract}
This study deals with the synthesis of a plant oil-based polymeric material from epoxidized soybean oil (ESO) and poly(butyl methacrylate) (PBMA). PolyESO/PBMAs were synthesized by an acid-catalyzed curing in the presence of PBMA to give a transparent bio-based polymeric material. During the reaction, the PBMA components scarcely reacted with ESO and were dispersed in the ESO polymer matrix to form semi-interpenetrating polymer network. The resulting polyESO/PBMA exhibited excellent flexibility. The incorporation of the PBMA components improved the mechanical properties of the plant oil-based network polymer. Furthermore, the polyESO/PBMA showed relatively good thermal stability. The present materials are expected to contribute to the development of bio-based polymeric materials.
\end{abstract}

Keywords: renewable resource, bio-based material, epoxidized soybeen oil, acrylic polymer

\section{Introduction}

Nowadays, there is a growing interest in green chemistry from the social and environmental viewpoints. A major principle in green chemistry is the use of renewable and sustainable raw materials that can introduce elements of degradability and reduced product toxicity in polymer production. Furthermore, the use of bio-based materials is highly significant for reduction of greenhouse gas and fossil resource-savings, which is one of the most promising solutions to problem concerning the global environment and energy resources (Nagarajan et al. 2013, Quirino et al. 2014, Dubé \& Salehpour 2014).

Among bioresources, plant oils, such as soybean oil, palm oil, canola oil, and sunflower oil, are expected as an ideal alternative chemical feedstock, since plant oils, derived from renewable resources, are found in abundance in the world. Plant oils consist of three fatty acids which are joined to glycerol by ester linkage, and the content of fatty acids and the number of unsaturated groups are characteristic for each plant oils. Inexpensive bio-based triglyceride have been utilized extensively for coatings, inks, plasticizers, lubricants, resins, and agrochemicals in addition to their applications in food industry (Biermann et al. 2000, Khot et al. 2001, Miyagawa et al. 2005, Metzger \& Bronscheuer 2006). However, these plant oil-based polymeric materials do not show sufficient rigidity and strength by themselves for structural applications. Therefore, plant oils were a minor component in polymeric materials; this is used solely as a modifier to improve their physical properties.

Epoxidized plant oils are found in naturally occurring oils, such as vernonia oil, and are easily synthesized from the unsaturated plant oils, such as linseed, sunflower, soybean, and palm oil, by standard epoxidation reaction. Epoxidized soybean oil (ESO) and epoxidized linseed oil are commercially available as a stabilizer and plasticizer for poly(vinyl chloride) and a modifier for coatings. Acrylates and polyols derived from epoxidized plant oils have also been used as a monomer for preparation of bio-based polymeric materials (Biresaw et al. 2008, Lligadas et al. 2010, Luo et al. 2011, Saithai et al. 2013). Furthermore, various cationic polymerization of epoxidized plant oil can be achieved by photoinitiators, latent catalysts, or acid catalysts (Chakrapani \& Crivello 1998, Shibata et al. 2009, Wang \& Schuman 2013). These epoxy compounds from renewable resources possess high potential as a starting material for bio-based thermosetting plastics (Tsujimoto et al. 2003, Petrović et al. 2005, Campanella et al. 2009, Gupta et al. 2011). Epoxidized plant oils were cured in the presence of inorganic chemicals to produce organic-inorganic hybrid materials 
(Uyama et al. 2003, Lligadas et al. 2006, Tanrattanakul \& Saithai 2009, Tsujimoto et al. 2015). Plant oil-based green composites were developed using biofiber (Williams \& Wool 2000, Rakotonirainy \& Padua 2001, Tran et al. 2006) and biopolymer (Imai et al. 2007, Ali et al. 2009, Hosoda et al. 2014), such as kenaf, flax, hemp, poly(lactic acid), and poly(3-hydroxybutyrate) as renewable compounds. By the incorporation of inorganic components, biofibers, or biopolymers, their mechanical strengths were effectively improved, whereas most of them showed poor flexibility due to the plant oil-based network structure.

This study deals with synthesis and properties of bio-based polymeric material from ESO and poly(butyl methacrylate) (PBMA). The resulting material exhibited excellent flexibility and relatively good transparency with increases in mechanical properties.

\section{Materials and Methods}

\subsection{Materials}

ESO was a gift from Adeka Co. PBMA was purchased from Sigma-Aldrich Co. The molecular weight of PBMA, determined by size exclusion chromatography (SEC), was $4.1 \times 10^{5}$. Thermally-latent cationic catalyst (a benzylsulfonium hexafluoroantimonate derivative, Sun Aid SI-60L) was provided by Sanshin Chemical Industry Co.

\subsection{Synthesis of polyESO/PBMA}

The synthesis of polyESO/PBMA was carried out as follows. ESO $(0.5 \mathrm{~g})$ and PBMA $(0.5 \mathrm{~g})$ were dissolved in $3.0 \mathrm{~mL}$ of chloroform, and a thermally-latent cationic catalyst was added to the solution. The resulting solution was poured into a Teflon mold $(17 \mathrm{~mm} \times 40 \mathrm{~mm} \times 1 \mathrm{~mm})$, and then, the solvent was allowed to evaporate at room temperature. The residual mixture was kept at $150{ }^{\circ} \mathrm{C}$ for $2 \mathrm{~h}$ to produce polyESO/PBMA $(50 / 50 \mathrm{wt} \%)$.

The polyESO/PBMAs with different feed ratio of ESO and PBMA were prepared by similar procedure.

\subsection{Measurements}

${ }^{1} \mathrm{H}$ nuclear magnetic resonance (NMR) spectrum was recorded on a Bruker Biospin DPX-400 instrument. SEC analysis was carried out by using a Tosoh SC8020 apparatus with a refractive index detector at $40{ }^{\circ} \mathrm{C}$ under the following conditions: Tosoh TSKgel G4000 column and chloroform eluent at a flow rate of $1.0 \mathrm{~mL} \cdot \mathrm{min}^{-1}$. The calibration curve was obtained using polystyrene standards. Fourier-transform infrared spectroscopy (FT-IR) was measured by a Perkin-Elmer Spectrum One. Dynamic viscoelasticity analysis (DMA) was performed by using an IT Instruments DVA-200 with a frequency of $1 \mathrm{~Hz}$ at a heating rate of $3{ }^{\circ} \mathrm{C} \cdot \mathrm{min}^{-1}$. Tensile properties were measured by a Shimadzu EZ Graph with a cross-head speed of $5 \mathrm{~mm} \cdot \mathrm{min}^{-1}$. The sample was cut into a plate shape of $10 \mathrm{~mm} \times 20 \mathrm{~mm} \times 1 \mathrm{~mm}$. Thermogravimetric (TG) analysis was performed using a Hitachi High-Tech Science TG/DTA7200 at a heating rate of $10^{\circ} \mathrm{C} \cdot \mathrm{min}^{-1}$ under nitrogen.

\section{Results and Discussion}

\subsection{Synthesis of polyESO/PBMA}

In this study, a bio-based polymeric material was synthesized from ESO and PBMA. The number of oxirane groups per an ESO molecule, determined by ${ }^{1} \mathrm{H}$ NMR, was 3.2. PBMA is one of acrylic polymers, which is an amorphous polymer with relatively low glass transition temperature. PBMA exhibits a flexible property and has been used for coating, adhesive, and sizing agent for paper. The crosslinking of ESO was carried out in the presence of PBMA using a thermally-latent acid as a catalyst to produce the bio-based polymeric material with high transparency (Figure 1). During the reaction, the oxirane groups of ESO reacted with each other to form the plant oil-based network structure. The resulting polyESO/PBMAs showed good transparency and flexibility, indicating that the PBMA components were dispersed in ESO polymer matrix.

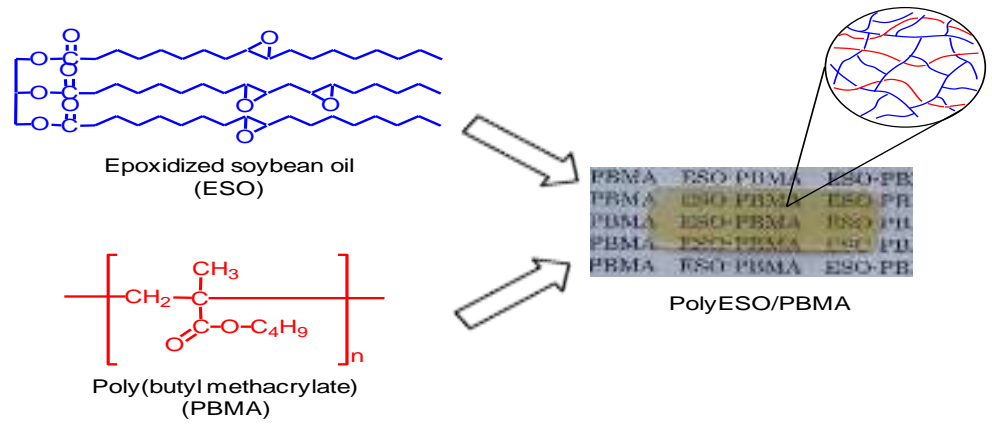

Figure 1. Synthesis of polyESO/PBMA. 
Figure 2 shows the FT-IR spectra of ESO, neat PBMA, and the polyESO/PBMA (50/50 wt\%). In the FT-IR spectrum of the polyESO/PBMA (50/50 wt\%), a characteristic peak at approximately $820 \mathrm{~cm}^{-1}$, ascribed to C-C antisymmetric stretching of the oxirane groups of ESO, decreased, and a broad peak centered at $3400 \mathrm{~cm}^{-1}$ due to $\mathrm{O}-\mathrm{H}$ vibration newly appeared. These data indicate that the oxirane groups of ESO react with each other to form plant oil-based network structure. On the other hand, the peaks at 1723 and $1741 \mathrm{~cm}^{-1}$ hardly changed. These peaks were derived from carboxyl groups of PBMA and ESO, respectively. The polyESO/PBMAs were immersed in chloroform for $24 \mathrm{~h}$, and the residue was washed with chloroform. The residual weight was close to the feed weight of ESO, because the PBMA components dissolved in chloroform. These results strongly suggest that the PBMA components scarcely reacted during the curing of ESO, and that semi-interpenetrating polymer network is formed.

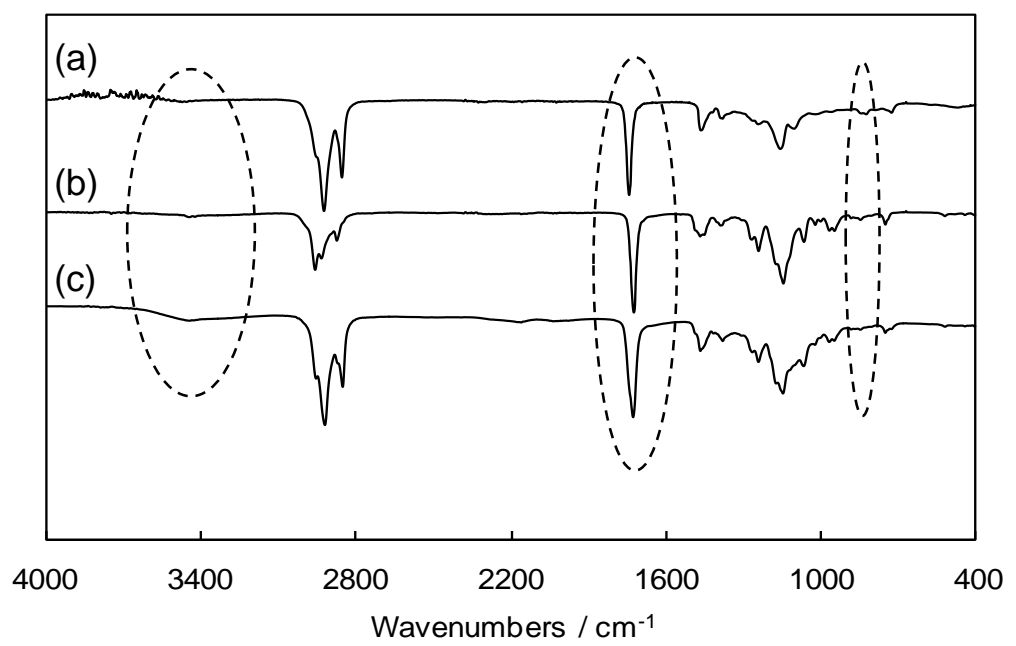

Figure 2. FT-IR spectra of (a) ESO, (b) neat PBMA, and (c) polyESO/PBMA

(A)

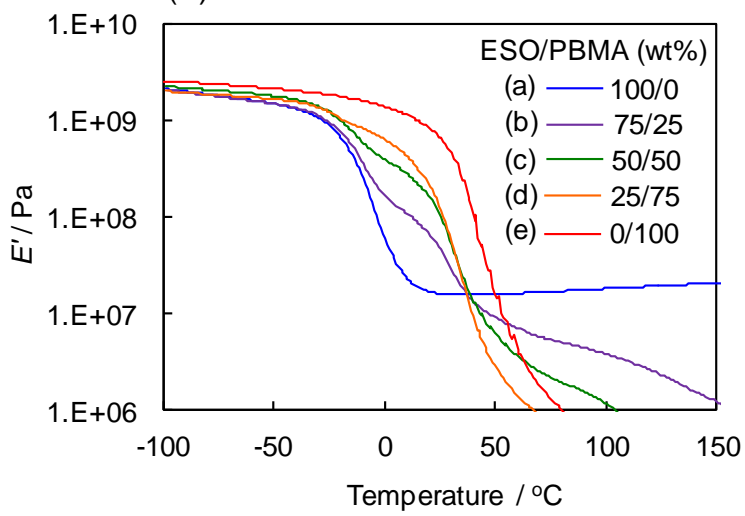

(B)

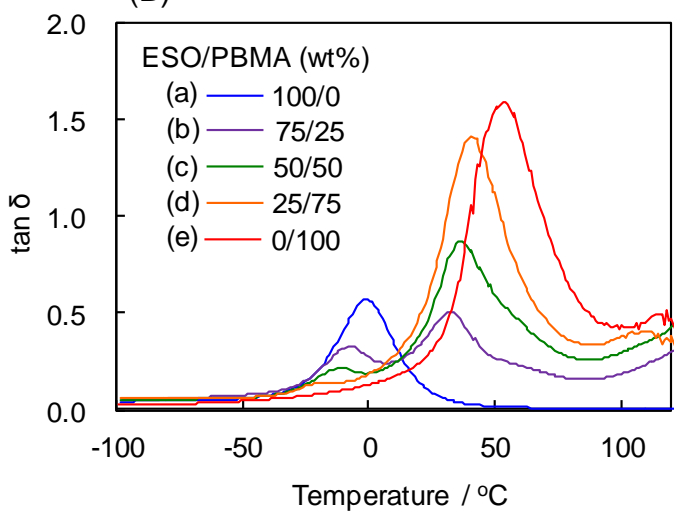

Figure 3. Dynamic viscoelasticity of (A) storage modulus, and (B) loss factor; (a) ESO homopolymer, (b) polyESO/PBMA (75/25 wt\%), (c) polyESO/PBMA (50/50 wt\%), (d) polyESO/PBMA (25/75 wt $\%$ ), and (e) neat PBMA

\subsection{Mechanical and Thermal Properties of polyESO/PBMA}

In order to investigate the effect of the incorporation of PBMA on the mechanical properties of the plant oil-based network polymer, the dynamic viscoelasticity analysis was carried out. Figure 3 shows storage moduli and loss factor curves as a function of temperature for the ESO homopolymer, the polyESO/PBMAs, and neat PBMA. For all samples, the storage moduli remained almost constant between -100 and $-40{ }^{\circ} \mathrm{C}$. The storage modulus of the ESO homopolymer decreased rapidly at $-25^{\circ} \mathrm{C}$, due to the glass transition of ESO-based network polymer. The storage modulus in rubbery region was constant with $10 \mathrm{MPa}$, suggesting the quantitative consumption of the oxirane groups of ESO. On the other hand, the storage modulus of neat PBMA dropped at $30{ }^{\circ} \mathrm{C}$, and PBMA became molten state. The storage moduli of polyESO/PBMAs decreased stepwise at approximately -10 and $30^{\circ} \mathrm{C}$, which were attributed to the glass transition of the ESO polymer and the PBMA component, respectively. The storage modulus of the polyESO/PBMAs at room 
temperature increased as the PBMA content increased, indicating effective reinforcement of the incorporation of the PBMA components. In loss factor curves of the polyESO/PBMAs, two peaks at approximately -10 and $35{ }^{\circ} \mathrm{C}$ were observed. This result indicates that the PBMA components are immiscible with ESO polymer. Furthermore, the peak with the lower temperature, which was derived from the glass transition of ESO polymer, shifted to lower temperature region. This may be because the incorporation of the PBMA components decreases the crosslinking density of the ESO-based network polymer.

To evaluate the reinforcement effect of the PBMA components, a tensile test was performed. The mechanical properties, such as tensile modulus, stress at break, and elongation, are summarized in Table 1. The ESO homopolymer was brittle, and fractured at low stress and strain, due to the ESO-based network structure. On the other hand, the polyESO/PBMAs exhibited ductile behaviors. The tensile modulus and the stress at break depended on the PBMA content, and they increased with increase in the PBMA content. The incorporation of the PBMA components also increased the elongation, and the elongation at break of the polyESO/PBMA (25/75 wt \%) was larger than that of neat PBMA. This is due to the plasticization effect of ESO. Furthermore, the polyESO/PBMAs showed excellent flexibility and could be easily bent (Figure 4). This characteristic property of the polyESO/PBMAs may be derived from the fine dispersion of the PBMA components in ESO matrix and the decrease of the crosslinking density of ESO-based network polymer.

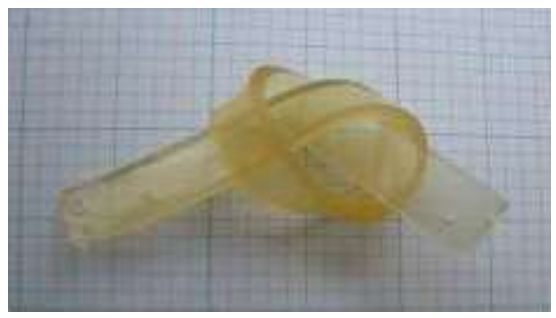

Figure 4. Photograph of flexible polyESO/PBMA (50/50 wt $\%)$

Table 1. Tensile properties of polyESO/PBMA

\begin{tabular}{cccc}
\hline Sample code & $\begin{array}{c}\text { Tensile modulus }^{\mathrm{a}} \\
\text { / MPa }\end{array}$ & $\begin{array}{c}\text { Stress at break }^{\mathrm{a}} \\
/ \mathrm{MPa}\end{array}$ & $\begin{array}{c}\text { Elongation }^{\mathrm{a}} \\
/ \%\end{array}$ \\
\hline ESO homopolymer & 7.2 & 0.4 & 7 \\
PolyESO/PBMA (75/25 & 12.1 & 1.3 & 37 \\
wt\%) & & & 47 \\
PolyESO/PBMA (50/50 & 56.6 & 2.5 & 305 \\
wt\%) & & 2.7 & 163 \\
PolyESO/PBMA (25/75 & 73.8 & 6.3 & \\
wt\%) & 324.4 & &
\end{tabular}

${ }^{a}$ Determined by tensile test.

The thermal stability of the polyESO/PBMA was evaluated by thermogravimetry (TG) under nitrogen. Figure 5 shows TG traces of the ESO homopolymer, neat PBMA, and the polyESO/PBMA (50/50 wt $\%$ ). The weight of the ESO homopolymer and neat PBMA decreased at approximately 370 and $250{ }^{\circ} \mathrm{C}$, respectively. The polyESO/PBMA (50/50 wt $\%$ ) was stable at a temperature lower than $280{ }^{\circ} \mathrm{C}$ and decomposed at around $300{ }^{\circ} \mathrm{C}$. Temperature at $5 \%$ weight loss of the ESO homopolymer, neat PBMA, and the polyESO/PBMA (50/50 wt\%) were 350, 237 and $299^{\circ} \mathrm{C}$, respectively. These data indicates relatively good thermal stability of the polyESO/PBMAs.

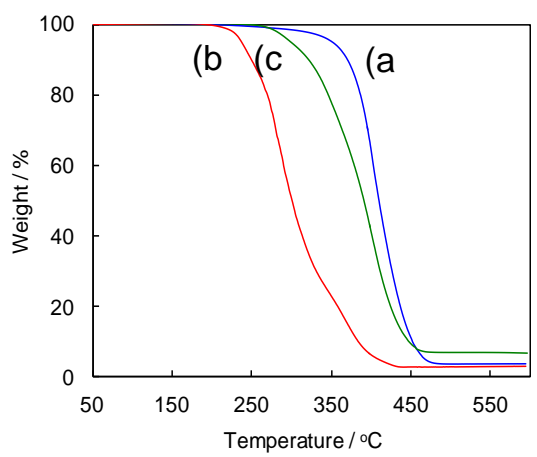

Figure 5. TG traces of (a) ESO homopolymer, (b) neat PBMA, and (c) polyESO/PBMA (50/50 wt\%). 


\section{Conclusion}

In this study, a new class of bio-based material from renewable plant oil was developed. The acid-catalyzed curing of epoxidized soybean oil in the presence of PBMA produced the transparent polymeric material with semi-interpenetrating network structure. The dynamic viscoelasticity analysis showed the reinforcement effect by the incorporation of the PBMA component. The tensile modulus and stress of the polyESO/PBMAs were larger than those of the ESO homopolymer. The elongation at break was also improved by the incorporation of PBMA components, and the polyESO/PBMAs exhibited excellent flexibility. Furthermore, the polyESO/PBMAs showed relatively good thermal stability.

Natural plant oils are renewable, nontoxic, and inexpensive materials. Thus, plant oil-based polymers and composites have large potential for industrial applications due to the low cost and the amorphous properties. This study provides new methodology of the preparation of high-performance bio-based polymeric materials.

\section{Acknowledgment}

This study was supported by a Grant-in-Aid for Young Scientists from Japan Society for the Promotion of Science (JSPS) (No. 268101140).

\section{References}

Ali, F., Chang, Y. W., Kang, S. C., \& Yoon, J. Y. (2009). Thermal, mechanical and rheological properties of poly(lactic acid)/epoxidized soybean oil blends. Polymer Bulletin, 62, 91-98. http://dx.doi.org/10.1007/s00289-008-1012-9

Biermann, U., Friedt, W., Lang, S., Lühs, W., Machmüller, G., Metzger, J. O., Rüsch gen. Klaas, M., Schäfer, H. J., \& Schneider, M. P. (2000). New syntheses with oils and fats as renewable raw materials for the chemical industry. Angewandte Chemie International Edition, 39, 2206-2224. http://dx.doi.org/10.1002/9783527619849.ch25

Biresaw, G., Liu, Z. S., \& Erhan, S. Z. (2008). Investigation of the surface properties of polymeric soaps obtained by ring-opening polymerization of epoxidized soybean oil. Journal of Applied Polymer Science, 108, 1976-1985. http://dx.doi.org/10.1002/app.27784

Campanella, A., La Scala, J. J., \& Wool, R. P. (2009). The use of acrylated fatty acid methyl esters as styrene replacements in triglyceride-based thermosetting polymers. Polymer Engineering \& Science, 49, 2384-2392. http://dx.doi.org/10.1002/pen.21486

Chakrapani, S., \& Crivello, J. V. (1998). Synthesis and photoinitiated cationic polymerization of epoxidized castor oil and its derivatives. Journal of Macromolecular Science, Part A, Pure and Applied Chemistry, 35, 1-20. http://dx.doi.org/10.1080/10601329808001959

Dubé, M. A., \& Salehpour, S. (2014). Applying the principles of green chemistry to polymer production industries. Macromolecular Reaction Engineering, 8, 7-28. http://dx.doi.org/10.1002/mren.201300103

Gupta, A. P., Ahmad, S., \& Dev, A. (2011). Modification of novel bio-based resin-epoxidized soybean oil by conventional epoxy resin. Polymer Engineering and Science, 51, 1087-1091. http://dx.doi.org/10.1002/pen.21791

Hosoda, N., Tsujimoto, T., \& Uyama, H. (2014). Plant oil-based green composite using porous poly(3-hydroxybutyrate). Polymer Journal, 46, 301-306. http://dx.doi.org/10.1038/pj.2014.1

Imai, N., Kageyama, H., \& Uyama, H. (2007). High-performance nanofiber-reinforced composite from all bio-based materials. Chemistry Letters, 36, 698-699. http://dx.doi.org/10.1246/cl.2007.698

Khot, S. N., Scala, J. J. L., Can, E., Morye, S. S., Williams, G. I., Palmese, G. R., Kusefoglu, S. H., \& Wool. R. P. (2001). Development and application of triglyceride-based polymers and composites. Journal of Applied Polymer Science, 82, 703-723. http://dx.doi.org/10.1002/app.1897

Lligadas, G., Ronda, J. C., Galià, M., \& Cádiz, V. (2006). Bionanocomposites from renewable resources: epoxidized linseed oil-polyhedral oligomeric silsesquioxanes hybrid materials. Biomacromolecules, 7, 3521-3526. http://dx.doi.org/10.1021/bm060703u

Lligadas, G., Ronda, J. C., Galià, M., \& Cádiz, V. (2010). Plant oils as platform chemicals for polyurethane synthesis: Current state-of-the-art. Biomacromolecules, 11, 2825-2835. http://dx.doi.org/10.1021/bm100839x

Luo, Q., Liu, M., Xu, Y., Ionescu, M., \& Petrović, Z. S. (2011). Thermosetting allyl resins derived from soybean oil. Macromolecules, 11, 7149-7157. 1 http://dx.doi.org/0.1021/ma201366e

Metzger, J. O., \& Bronscheuer, U. (2006). Lipids as renewable resources: current state of chemical and biotechnological conversion and diversification. Applied Microbiology and Biotechnology, 71, 13-22. http://dx.doi.org/10.1007/s00253-006-0335-4 
Miyagawa, H., Misra, M., Drazal, L. T., \& Mohanty, A. K. (2005). Novel biobased nanocomposites from functionalized vegetable oil and organically-modified layered silicate clay. Polymer, 46, 445-453. http://dx.doi.org/10.1016/j.polymer.2004.11.031

Nagarajan, V., Mohanty, A. K., \& Misra, M. (2013). Sustainable green composites: Value addition to agricultural residues and perennial grasses. ACS Sustainable Chemisry \& Engineering, 1, 325-333. http://dx.doi.org/10.1021/sc300084z

Petrović, Z. S., Zhang, W., \& Javni, I. (2005). Structure and properties of polyurethanes prepared from triglyceride polyols by ozonolysis. Biomacromolecules, 6, 713-719. http://dx.doi.org/10.1021/bm049451s

Quirino, R. L., Garrison, T. F., \& Kessler, M. R. (2014). Matrices from vegetable oils, cashew nut shell liquid, and other relevant systems for biocomposite applications. Green Chemistry, 16, 1700-1715. http://dx.doi.org/10.1039/C3GC41811A

Rakotonirainy, A. M., \& Padua, G. W. (2001). Effects of lamination and coating with drying oils on tensile and barrier properties of zein films. Journal of Agricultural and Food Chemistry, 49, 2860-2863. http://dx.doi.org/10.1021/jf000845u

Saithai, P., Lecomte, J., Dubreucq, E., \& Tanrattanakul, V. (2013). Effects of different epoxidation methods of soybean oil on the characteristics of acrylated epoxidized soybean oil-co-poly(methyl methacrylate) copolymer. eXPRESS Polymer Letters, 7, 910-924. http://dx.doi.org/10.3144/expresspolymlett.2013.89

Shibata, M., Teramoto, N., Someya, Y., \& Suzuki, S. (2009). Bio-based nanocomposites composed of photo-cured epoxidized soybean oil and supramolecular hydroxystearic acid nanofibers. Journal of Polymer Science Part B: Polymer Physics, 47, 669-673. http://dx.doi.org/10.1002/polb.21671

Tanrattanakul, V., \& Saithai, P. (2009). Mechanical properties of bioplastics and bioplastic-organoclay nanocomposites prepared from epoxidized soybean oil with different epoxide contents. Journal of Applied Polymer Science, 114, 3057-3067. http://dx.doi.org/10.1002/app.30842

Tran, P., Graiver, D., \& Narayan, R. (2006). Biocomposites synthesized from chemically modified soy oil and biofibers. Journal of Applied Polymer Science, 102, 69-75. http://dx.doi.org/10.1002/app.22265

Tsujimoto, T., Uyama, H., \& Kobayashi, S. (2003). Green nanocomposites from renewable resources: Biodegradable plant oil-silica hybrid coatings. Macromolecular Rapid Communications, 24, 711-714. http://dx.doi.org/10.1002/marc.200350015

Tsujimoto, T., Uyama, H., Kobayashi, S., Oikawa, H., \& Yamahiro, M. (2015). Green nanocomposites from renewable plant oils and polyhedral oligometric silsesquioxanes. Metals, 5, 1136-1147. http://dx.doi.org/10.3390/met5031136

Uyama, H., Kuwabara, M., Tsujimoto, T., Nakano, M., Usuki, A., \& Kobayashi, S. (2003). Green nanocomposites from renewable resources: Plant oil-clay hybrid materials. Chemistry of Materials, 15, 2492-2494. http://dx.doi.org/10.1021/cm0340227

Wang, R., \& Schuman, T. P. (2013). Vegetable oil-derived epoxy monomers and polymer blends: A Comparative Study with Review. eXPRESS Polymer Letters, 7, 272-292. http://dx.doi.org/10.3144/expresspolymlett.2013.25

Williams, G. I., \& Wool, R. P. (2000). Composites from natural fibers and soy oil resins. Applied Composite Materials, 7, 421-432. http://dx.doi.org/10.1023/A:1026583404899

\section{Copyrights}

Copyright for this article is retained by the author(s), with first publication rights granted to the journal.

This is an open-access article distributed under the terms and conditions of the Creative Commons Attribution license (http://creativecommons.org/licenses/by/3.0/). 